\title{
Dynamic Response of Wheel-Rail Interaction at Rail Weld in High-Speed Railway
}

\author{
Boyang An, ${ }^{1,2}$ Ping Wang, ${ }^{1,2}$ Jieling Xiao, ${ }^{1,2}$ Jingmang $X u^{1,2}$ and Rong Chen ${ }^{1,2}$ \\ ${ }^{1}$ MOE Key Laboratory of High-Speed Railway Engineering, Southwest Jiaotong University, Chengdu 610031, China \\ ${ }^{2}$ School of Civil Engineering, Southwest Jiaotong University, Chengdu 610031, China \\ Correspondence should be addressed to Jingmang Xu; mang080887@163.com and Rong Chen; chenrong@home.swjtu.edu.cn
}

Received 10 June 2017; Accepted 6 November 2017; Published 7 December 2017

Academic Editor: Chao Tao

Copyright (c) 2017 Boyang An et al. This is an open access article distributed under the Creative Commons Attribution License, which permits unrestricted use, distribution, and reproduction in any medium, provided the original work is properly cited.

\begin{abstract}
As a main part of continuously welded rail track, rail weld widely exists in high-speed railway. However, short-wave irregularities can easily initiate and develop in rail weld due to the limitation of welding technology and thus rail weld has been a main high-frequency excitation and is responsible for deterioration of track components. This work reports a 3D finite element model of wheel-rail rolling contact which can simulate dynamic wheel-rail interaction at arbitrary contact geometry up to $400 \mathrm{~km} / \mathrm{h}$. This model is employed to investigate dynamic response of wheel-rail interaction at theoretical and measured rail weld, including wheel-rail force and axlebox acceleration. These simulation results, combined with Quality Index (QI) method, are used to develop a quantitative expression, which can be easily applied for evaluating rail weld deterioration based on measured rail profiles and axle-box acceleration.
\end{abstract}

\section{Introduction}

Rails of standard length can be welded into required length in the continuously welded track to eliminate the joint gaps $[1,2]$ (see Figure 1). This method is able to improve the continuity and integrity of the track structure, provide a good riding performance, extend service life of rails, and decrease labor in maintenance, which has been widely accepted in the railway. However, the geometrical profiles of rail welds are hardly to maintain due to the limitation of the welding process and the improper operation [3], the phase transformation between welding materials and base metals [4], and the influence of residual stress [5] and fatigue crack [6]. This phenomenon has been recently observed by Gao et al. [1] who conducted detailed measurement and statistics on the geometric irregularity of rail welds in Chinese high-speed lines and found that short-wave irregularity is a main form of surface defects in the rail weld zones.

Initiation and development of the short wavelength irregularity can be a high-frequency excitation of wheel-rail system, and excited high impact finally loses its energy by dissipation in the form of plastic deformation, wear, and other forms of track damage. Therefore, controlling the size of weld irregularity is of great importance to ensure secure, stable, and economic operation of high-speed railway. In China, the straightness shall not exceed $0.3 \mathrm{~mm}$ and $0.2 \mathrm{~mm}$ at the operating speeds of $200 \mathrm{~km} / \mathrm{h}$ and $300 \mathrm{~km} / \mathrm{h}$, respectively, within the straightedge measuring range of $1 \mathrm{~m}$ in Chinese maintenance regulation for high-speed nonballast track lines. Obviously, this standard ignores the influence of geometrical wavelengths on wheel-rail force. Zhai et al. [7] developed a vehicle-track coupling dynamic model to investigate dynamic behavior induced by rail weld and suggest some maintenance standard for speed-raised lines. Xiao et al. [8] found that the wheel-rail force at the rail weld increases with the decrease of the wavelength and propose safety limits under different speed against the irregularity of rail welds based on dynamics index or dynamic factors. However, weld irregularities in $[7,8]$ were modelled as ideal cosine waveform and different from the actual weld geometry. Thus, conclusions of the above researches are difficult to be applied in the maintenance of actual lines. Steenbergen and Esveld $[9,10]$ evaluated the quality of rail welds using a geometric gradient (the QI method) which can be used for considering any weld geometric forms. Then, in their products [11], some safety thresholds in reference to geometric gradients up to $300 \mathrm{~km} / \mathrm{h}$ have also been determined according to numerical simulation and engineering experience. But these thresholds of [11] 


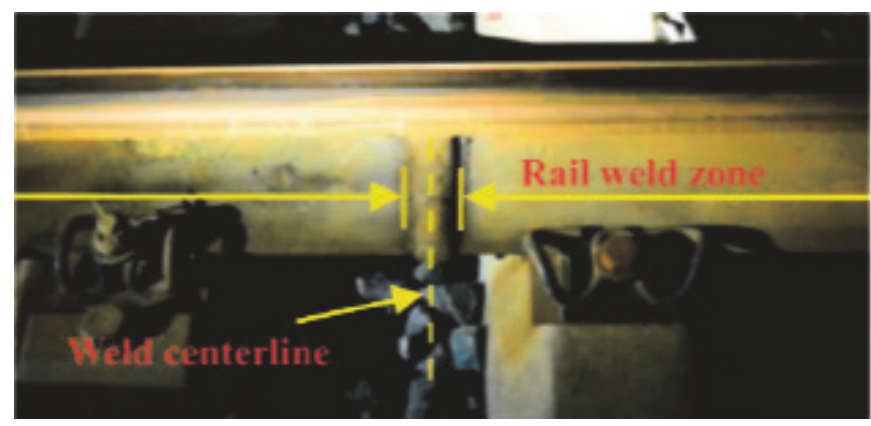

(a)

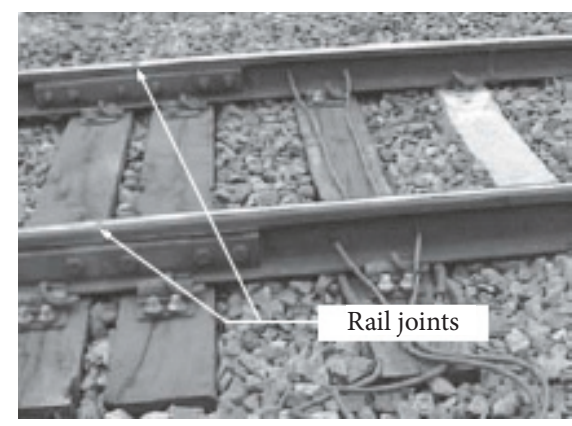

(b)

Figure 1: (a) Rail weld [1] and (b) rail joint [2].

were only established based on the linear relation between geometric gradient and dynamic force to satisfy engineering requirements with the dynamic force of $11 \mathrm{kN}$ as a limiting indicator of track quality evaluation for new built lines or after grinding maintenance. $90 \mathrm{kN}$ is generally regarded as the safety limit in China to control the dynamic interaction of wheels and rails in daily operation [12]. Therefore, it shall establish a more precise relationship between geometric gradient and dynamic force to serve the maintenance of the railway department.

The precondition of carrying out the evaluation of wheelrail force at rail welds stated in the last paragraph is to obtain its geometric size, which generally is high time- and manpower-consuming. By contrast, detection of axle-box acceleration is a simple and economical method, whose advantage is that accelerometer can be easily installed on existing standard vehicles without limitation of running speed of vehicles [13]. Thereby, international scholars have made attempts to detect the irregularity of wheel-rail interface through the response of axle-box acceleration. Liang et al. [14] developed a set of indoor rolling test devices for simulating the response of axle-box acceleration at speed conditions ranging from 3.5 to $15 \mathrm{~km} / \mathrm{h}$ when there were flaws on the wheel-rail surface. Obvious fluctuations of axlebox acceleration were generated at the damage. Molodova et al. $[15,16]$ carried out corresponding tests of axle-box acceleration (with the vehicle speed of $100 \mathrm{~km} / \mathrm{h}$ ) against some damage occurring at weld joints on site with preliminary establishment of a health monitoring system that can detect components in bad service statuses. Molodova et al. [17] simulated the changes of axle-box acceleration at shortwave irregularities of rail at a speed of $140 \mathrm{~km} / \mathrm{h}$ by using 3D explicit finite element model and results conforming to the site test were obtained. It shall be noted that main purpose of above studies was to monitor defects through the dynamic response in time and frequency domain. Thus, the relationship between the axle-box acceleration and the wheel-rail force was not given, and axle-box acceleration cannot be quantitatively used to limit dynamic force at rail weld.

As mentioned above, geometric gradient-dependent wheel-rail force and axle-box acceleration are feasible and reliable methods for assessing rail weld. But an exact quantitative relation among geometrical gradient, wheel-rail force, and axle-box acceleration still lacks for high-speed railway, which facilitates the scope of this paper. Based on previous study [18], this paper employs a 3D wheel-rail rolling contact model to solve the dynamic interaction at the theoretical and measured rail welds. Wheel-rail force and axle-box acceleration induced by theoretical rail welds are firstly obtained, which contribute to the establishment of quantitative expression with geometric gradient. Then this expression is used to evaluate wheel-rail force based on measured rail profiles and axle-box acceleration. In the end of this paper, it discusses the evolution of rail weld irregularity.

\section{Transient Finite Element Model of Wheel-Rail Rolling Contact in 3D}

2.1. Method Selection. In the past, the calculation of dynamic wheel-rail interaction was widely used in the multibody dynamic model [1, 2, 7-10]. The wheelset in these models was generally considered as a rigid body, so that the response of axle-box acceleration, which oscillates as local vibration, cannot be obtained. In addition, the stiffness coefficient of the normal contact spring used in the traditional vehicletrack coupling dynamics model is generally derived from the Hertz theory based on the static hypothesis, which contains some differences when dynamic interaction between wheel and rail is taken into account [19]. Moreover, as vehicle speed increases, wheel-rail high-frequency vibration inspired by short wavelength irregularity cannot be ignored [20]. To represent this characteristic, wheel and rail should be modelled as solid element but not beam as in traditional vehicle-track coupling dynamics model [1,7-10]. Considering the above three factors, a 3D high-speed wheel-rail rolling contact FE model (hereinafter referred to as rolling model) is established in this section to accurately solve the dynamic contact behavior at the rail welds.

2.2. Finite Element Modelling. The established rolling model based on Chinese high-speed railway is shown in Figure 2. Considering that the vehicle-track system is symmetrical along the center line of the track, only half of wheelset and track were simulated to improve the computational efficiency. The sprung mass was simplified as a mass and connected 


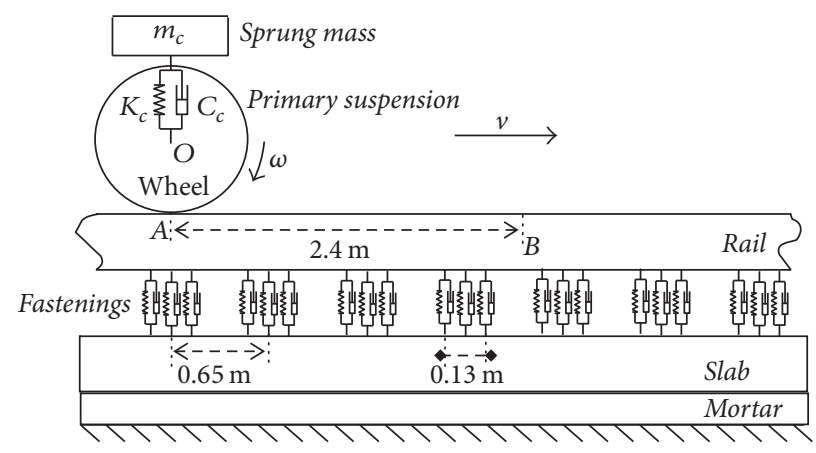

(a) The schematic diagram

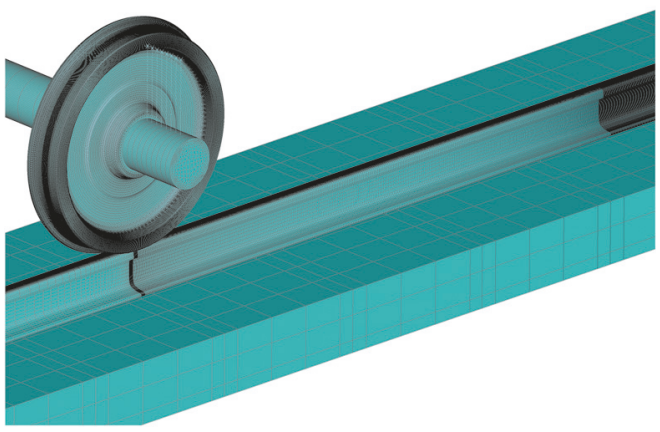

(b) The mesh

FIGURE 2: 3D wheel-rail rolling contact finite element model.

to the wheel by the primary suspension. The simulated nonballast track contained rails, fastening, slab, and mortar.

In order to reflect the high-frequency vibration response of the wheel-rail system, the solid element was used for meshing the wheel and rail; also, the nonuniform meshing was imposed to lower the model scale. The minimum element size was $1.1 \mathrm{~mm}$ in wheel-rail contact surface. The profiles of wheel and rail were, respectively, modelled as LMa and CN60, and the track cant of $1: 40$ was considered. The rolling contact between the wheel and rail was solved in the time domain by the penalty method. This method is used to enforce the contact constraints, where a set of invisible "interface spring" elements are placed between all the penetrating slave segments and the master segments [19]. The fastening system was simulated by a spring-damping coupling element. In addition, track and mortar also adopted 8-node solid elements to divide the grid to fully reflect its vibration characteristics. Parameters of each component are listed in Table 1.

2.3. Rail Weld and Its Geometric Gradient. With smooth wheel-rail surface upon mesh generation, the 3D geometry irregularity of rail weld was realized through modifying coordinate of related nodes belonging to the rail surface by self-compiled program.

A series of theoretical and measured geometries were simulated in the paper. For the theoretical geometry, the vertical coordinate $z$ in the longitudinal direction is shown in the following formula:

$$
z=\frac{\delta}{2}\left(1+\cos \frac{2 \pi x}{\lambda}\right)
$$

where $\delta$ and $\lambda$ are the wave depth and length of the weld; $x$ follows the longitudinal direction. The horizontal geometry is distributed in parabolic type, whose function is expressed as follows:

$$
z=\left[1-\left(\frac{y}{w}\right)^{2}\right] \cdot \delta,
$$

where $w$ is a half of the weld width, which is simulated as $15 \mathrm{~mm}$ according to field observation.
TABLE 1: Values of parameters involved in the model.

\begin{tabular}{lc}
\hline Parameters & Values \\
\hline Lumped sprung mass & $7500 \mathrm{~kg}$ \\
Stiffness of primary suspension & $880 \mathrm{kN} / \mathrm{m}$ \\
Damping of primary suspension & $4 \mathrm{kNs} / \mathrm{m}$ \\
Stiffness of fastenings & $22 \mathrm{MN} / \mathrm{m}$ \\
Damping of fastenings & $200 \mathrm{kNs} / \mathrm{m}$ \\
Wheel and rail material & \\
Young's modulus & $205.9 \mathrm{GPa}$ \\
Poisson's ratio & 0.3 \\
$\quad$ Density & $7790 \mathrm{~kg} / \mathrm{m}^{3}$ \\
Material of prefabricated slabs & \\
Young's modulus & $34.5 \mathrm{GPa}$ \\
Poisson's ratio & 0.25 \\
Density & $2400 \mathrm{~kg} / \mathrm{m}^{3}$ \\
Mortar material & \\
Young's modulus & $8 \mathrm{GPa}$ \\
Poisson's ratio & 0.2 \\
Density & $1600 \mathrm{~kg} / \mathrm{m}^{3}$ \\
\hline
\end{tabular}

First-order derivative is solved from (1) to obtain the geometric gradient's expression of theoretical weld:

$$
\frac{d z}{d x}=-\frac{\delta \pi}{\lambda} \sin \frac{2 \pi x}{\lambda}
$$

Taking $1 \mathrm{~m}$ of wavelength as an example, the theoretical weld geometry and its gradient change under depth of $0.2 \mathrm{~mm}$ are presented in Figure 3. As $z$ increases, the gradient shows a sine change, reaching the maximum at the $1 / 4$ wavelength of the weld. When the gradient is greater than zero, $z$ increases with the increment of $x$, while it is on the contrary for a negative gradient. As a result, the three zero points of the gradient correspond to the starting, peak, and end points of rail weld, respectively. The first two of these points obviously determine the depth $d$, which triggers an approach defining the characteristic depth of measured rail weld, and it is presented in Section 5.1 for engineering application. 


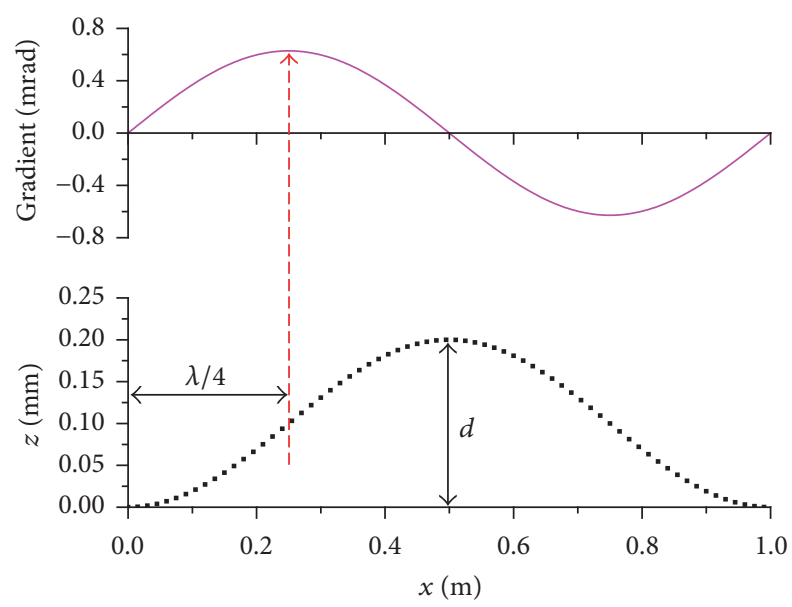

FIgURE 3: Theoretical rail weld geometry and its gradient change.

Four measured geometries named RW1 4 in Figure 4(a) were also simulated for the explanation of engineering application (see Section 5.1), and Figure 4(b) is an example of RW3 in 3D. Note that field measurements were done with the RAILPROF device on a base with the length of $1 \mathrm{~m}$ along the longitudinal direction for the whole flash-butt welding zone at an interval of $5 \mathrm{~mm}$. The track is nonballast track, containing rail, fastening, slab, and mortar, which is widely used in Chinese high-speed railway. The operation speed of this railway is $300 \mathrm{~km} / \mathrm{h}$.

2.4. Simulation Process. Implicit-explicit analysis as shown in Figure 5 was adopted in the simulation to treat the wheel-rail rolling contact behavior. It firstly adopts implicit algorithm to solve the static contact in initial position A (see Figure 2(a)) and then initialize the explicit algorithm with the vehicle rolling forwards at a constant speed $v$. Boundary conditions are applied as follows: symmetric boundary conditions are applied to the axle ends of the wheelset and to the rail ends; the bottom of the mortar layer is fixed; the fastenings, the slabs, and the mortar layer can only move vertically. For more information on the modelling approach, the readers are referred to [21].

\section{Dynamic Response of Wheel-Rail Interaction at Theoretical Rail Weld}

3.1. Dynamic Wheel-Rail Force. The dynamic wheel-rail force (hereinafter referred to as dynamic force and defined in (4)) inspired by the rail weld at a speed of $300 \mathrm{~km} / \mathrm{h}$ is shown in Figure 6(a). The depth of the weld is $0.2 \mathrm{~mm}$ with wavelengths of $0.05 \mathrm{~m}$ and $0.5 \mathrm{~m}$. Taking the condition of $0.05 \mathrm{~m}$ as an example, the impact of dynamic force is caused by the geometric irregularity of rail weld with the maximum value of $91.2 \mathrm{kN}$ and then fluctuates after passing over the weld. In contrast, the dynamic force vibrates gently in the case of $0.5 \mathrm{~m}$, because the long wavelength irregularity is difficult to stimulate the high-frequency vibration of the vehicle-track system.

$$
F_{\text {dyn }}=F_{\text {max }}-F_{\text {static }}
$$

where $F_{\max }$ and $F_{\text {static }}$ are the maximum wheel-rail force and the static wheel load, respectively.

The change of the maximum dynamic force along with the wavelength (from 0.03 to $0.5 \mathrm{~m}$ ) is shown in Figure 6(b), and the results of [10] are also included in the figure for comparison. It can be seen from the figure that the maximum dynamic force decreases with the increment of the weld wavelength. By comparison of calculated results of both models, it can be found that the maximum dynamic force obtained by the rolling model is smaller. And this difference increases with the decrease of the wavelength; that is, the short-wave irregularities trigger a great difference. The reason for this phenomenon is that the wheel was simplified as a mass point in the method of [10] with the beam element to characterize the rail, and the wheel-rail contact is expressed by a Hertz spring. In this way, the assumption of infinitely small wheelrail contact patch exaggerates the contact stiffness. Another reason lies in the fact that it is difficult for the beam element to simulate the local vibration by short-wave irregularities. Note that the maximum dynamic force in rolling model will not be infinitely increased as the wavelength decreases. The reason for this phenomenon is the filtering effect of the contact patch or the so-called contact filter. That is, the surface irregularities whose wavelengths are smaller than or close to the contact patch's size cannot effectively excite strong vibration.

3.2. Axle-Box Acceleration. When the vehicle is running at the speed of $300 \mathrm{~km} / \mathrm{h}$, the time course changes of axle-box acceleration excited by the weld (with the wavelength and the depth of $0.1 \mathrm{~m}$ and $0.2 \mathrm{~mm}$, resp.) are shown in Figure 7. Taking into account the fact that axle-box acceleration signals measured on site are often processed through the low-pass filter (LPF) to eliminate the high-frequency noise interference, $1500 \mathrm{~Hz}$ LPF change is imposed on the simulated result for the application in the processing of measured data. When passing the weld, ABA shows a strong vibration and the maximum value is $190.7 \mathrm{~m} / \mathrm{s}^{2}$. Compared with results in Figure 6(a), only one impact occurs in the dynamic force, while the ABA is vibrated continuously. That is to say, acceleration is more sensitive to the impact.

\section{Relation of Geometric Gradient, Dynamic Wheel-Rail Force, and Axle-Box Acceleration}

4.1. Steenbergen's QI Method. Steenbergen and Esveld [9] deduced and validated a mathematical expression of rail welding's geometric gradient and its stimulated maximum dynamic force $F_{\text {dyn,max }}$ in a linear relation:

$$
F_{\text {dyn,max }}=k \cdot\left|\frac{d z}{d x}\right|_{\text {max }},
$$

where $k$ is a dimensionless parameter and varies for different running speed of vehicle. 


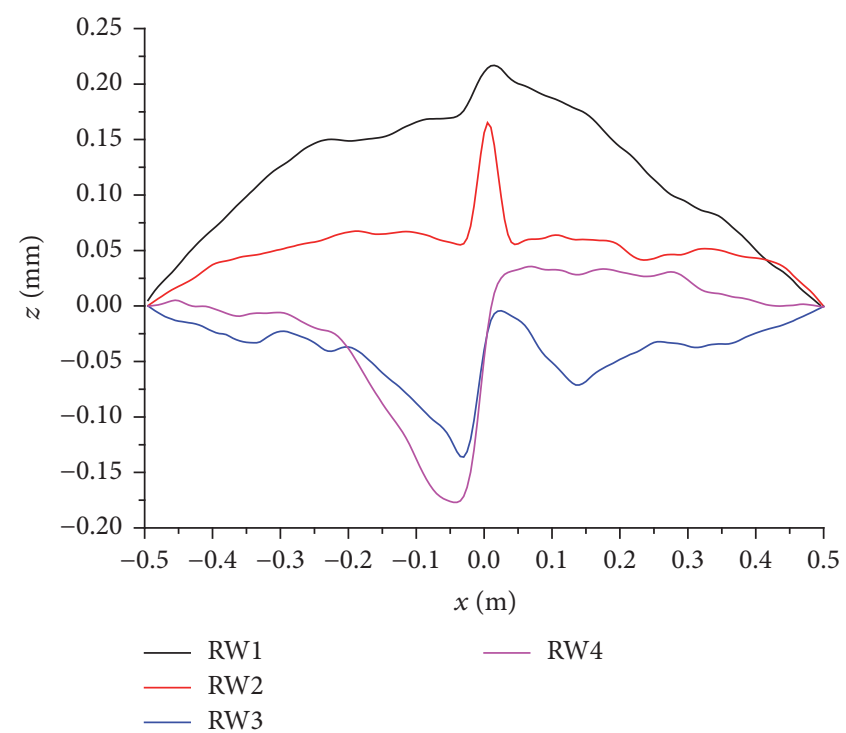

(a)

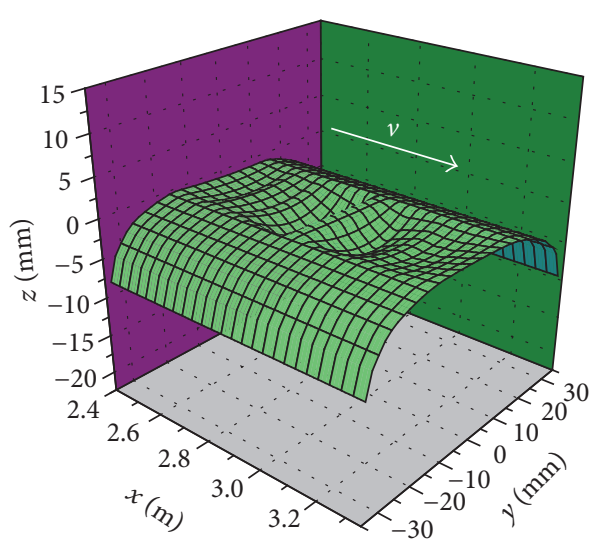

(b)

FIGURE 4: Measured rail welds: (a) in $x-z$ plane and (b) RW3 in 3D (depth is amplified by 20 times for easy visualization).

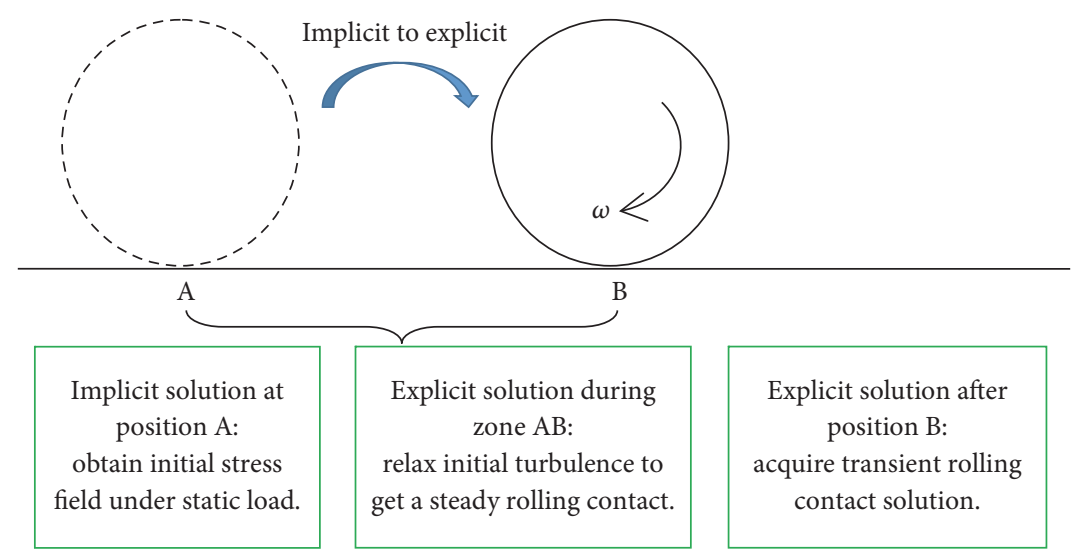

FIGURE 5: Schematic diagram of simulation process.

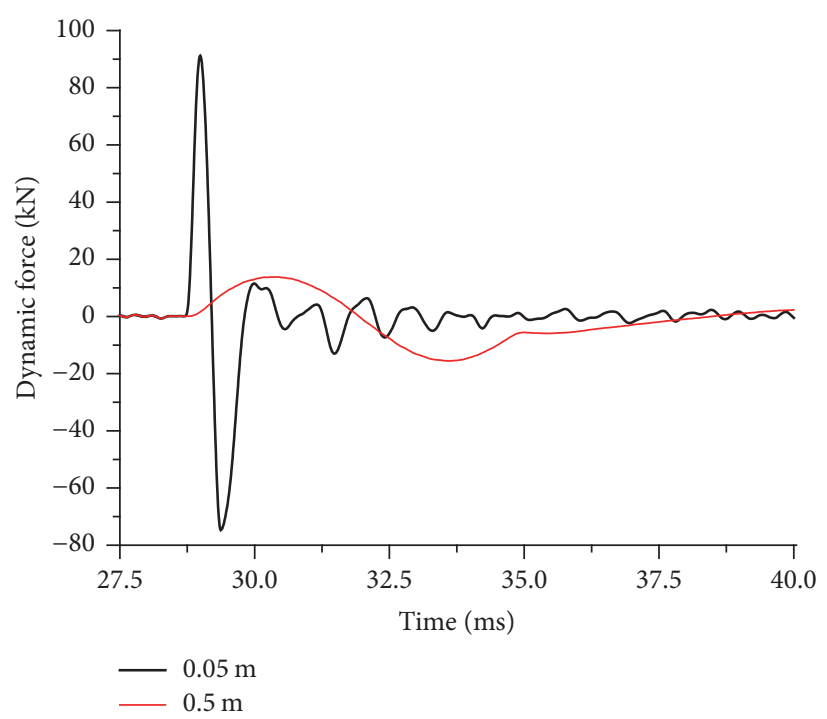

(a)

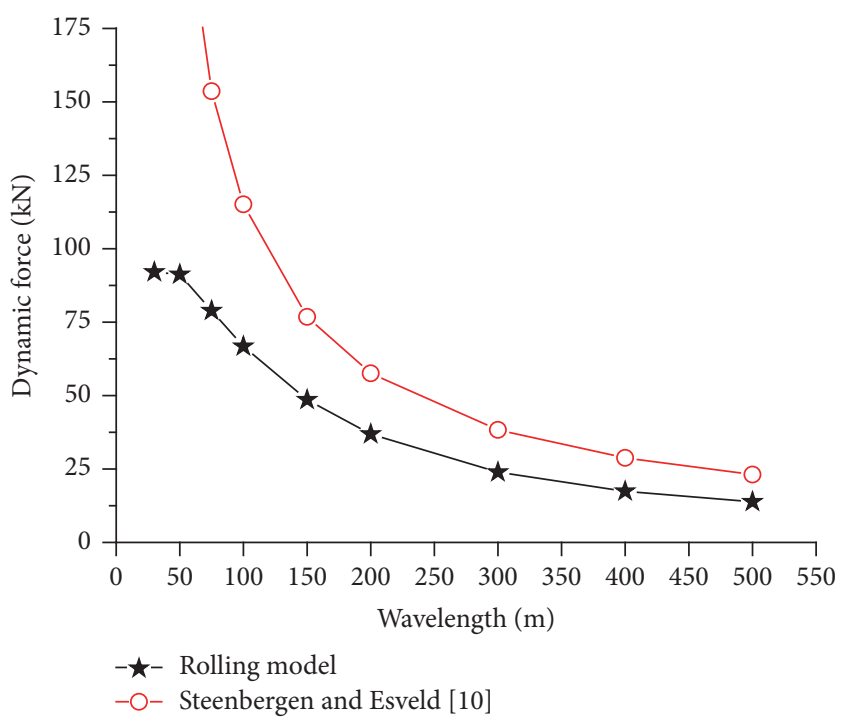

(b)

FIgURE 6: Variation of dynamic force with (a) the time and (b) the wavelength under $300 \mathrm{~km} / \mathrm{h}$. 


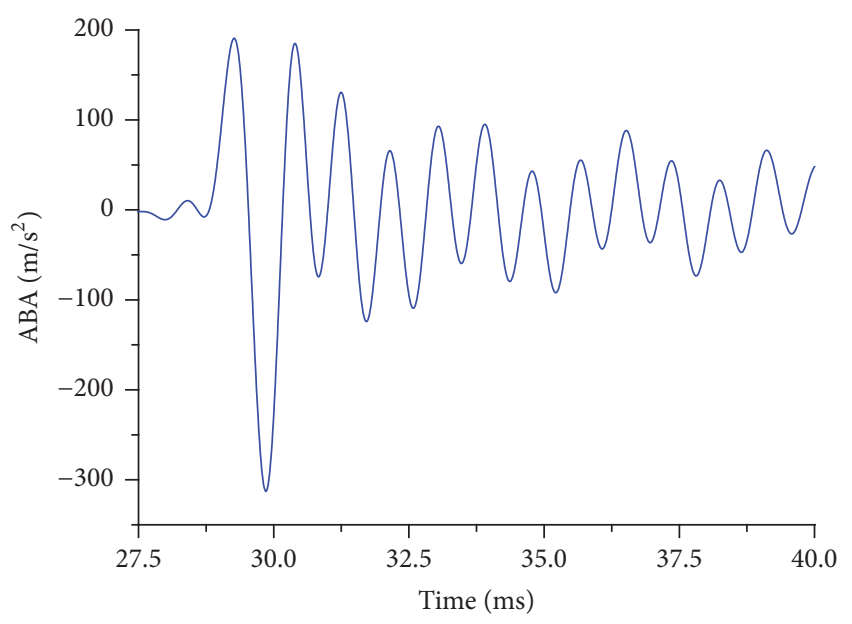

FIGURE 7: The response of axle-box acceleration under excitation of rail weld (the wavelength and depth are $0.1 \mathrm{~m}$ and $0.2 \mathrm{~mm}$, resp.) under $300 \mathrm{~km} / \mathrm{h}$.

In [10], the gradient corresponding to $F_{\text {dyn,max }}$ of $11 \mathrm{kN}$ is regarded as the intervention value $I$ to control the irregularity:

$$
I=\frac{11}{k}
$$

QI (Quality Index) value is defined as the ratio of the maximum geometric gradient and the intervention value as follows:

$$
\mathrm{QI}=\frac{|d z / d x|_{\max }}{I}
$$

It is obvious that the rail weld with a QI value below 1 meets the criteria.

\subsection{Quantitative Relation of Geometric Gradient and Dynamic} Wheel-Rail Force. The variation of maximum dynamic force with the gradient is presented in Figure 8, covering three depths of $0.1,0.2$, and $0.3 \mathrm{~mm}$ with wavelength ranging from 0.03 to $1 \mathrm{~m}$. The condition of $0.2 \mathrm{~mm}$ depth is illustrated as an example. When the gradient is less than 4.19 , the maximum dynamic force and the gradient are presented in linear changes. The linear fitting formula is expressed as shown in the figure (the slope of the formula is $k$ in formula (5)). With the increase of the gradient, the nonlinearity of the curve is gradually strengthened to reach the extreme value of $92 \mathrm{kN}$. When the depth is $0.3 \mathrm{~mm}$, the extreme value is $133.5 \mathrm{kN}$ and is close to the safety ultimate $(150 \mathrm{kN}$ or DAF $=3)$ of design. As maintenance such as rail grinding or replacing is timeconsuming, it is appropriate to control the straightness of rail welds within $0.2 \mathrm{~mm}$ at the speed of $300 \mathrm{~km} / \mathrm{h}$ to ensure adequate margins for safety. For easy engineering application, the curve of geometrical gradient versus dynamic force has

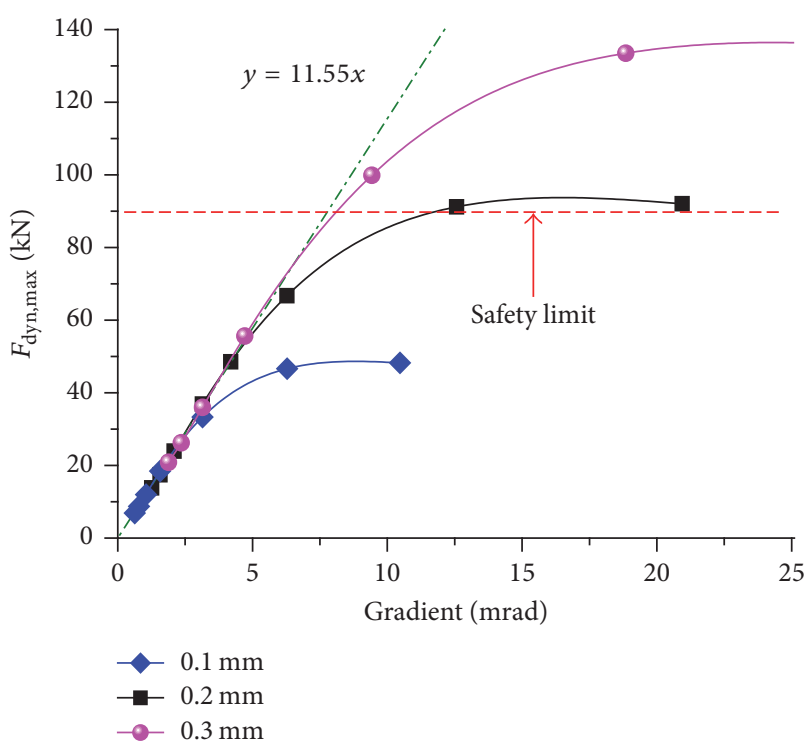

FIGURE 8: The change of maximum dynamic force with the gradient under three depths.

been fitted at different depths. The expression is presented as follows:

$$
\begin{aligned}
{\left[\begin{array}{l}
y_{1} \\
y_{2} \\
y_{3}
\end{array}\right]=} & {\left[\begin{array}{lll}
0.0332 & -1.2611 & 14.2623 \\
0.0102 & -0.7002 & 14.7074 \\
0.0049 & -0.4848 & 14.7246
\end{array}\right] \cdot\left[\begin{array}{l}
g^{3} \\
g^{2} \\
g
\end{array}\right] } \\
& -\left[\begin{array}{l}
1.0383 \\
2.4188 \\
3.5505
\end{array}\right]
\end{aligned}
$$

where $\left[\begin{array}{lll}y_{1} & y_{2} & y_{3}\end{array}\right]^{\prime}$ represents the dynamic force of the depth ranging from 0.1 to $0.3 \mathrm{~mm} ; g$ is the geometric gradient.

Figure 9(a) further gives the change of maximum dynamic forces with the gradient under the speed range from 200 to $400 \mathrm{~km} / \mathrm{h}$, and the depth of the weld is selected as $0.2 \mathrm{~mm}$. With the increase of the speed, the nonlinearity of the curve gradually enhances. The corresponding gradient threshold value of the linear region decreases from 6.28 to 3.14, while the slope increases from 7.78 to 15.7. Based on these results, the intervening values defined in formula (4) at $200 \sim 400 \mathrm{~km} / \mathrm{h}$ are $1.41,0.95$, and 0.7 , respectively. According to the criteria used in RAILPROF (a device assessing rail weld) [11], the intervention values are 1.3 and 1 for 200 and $300 \mathrm{~km} / \mathrm{h}$, respectively. The comparison is shown in Figure 9(b), intervention values obtained by this paper and proposed by RAILPROF are almost the same. As RAILPROF has been used widely [9-11], the curve relationship between the dynamic force and the gradient curve obtained by the theoretical geometries is reliable and can be applied to acquire dynamic force at measured rail welds. It is worth pointing out that no intervention value for $400 \mathrm{~km} / \mathrm{h}$ is provided in RAILPROF, and this value is suggested as 0.7 according to simulated results by rolling model. 


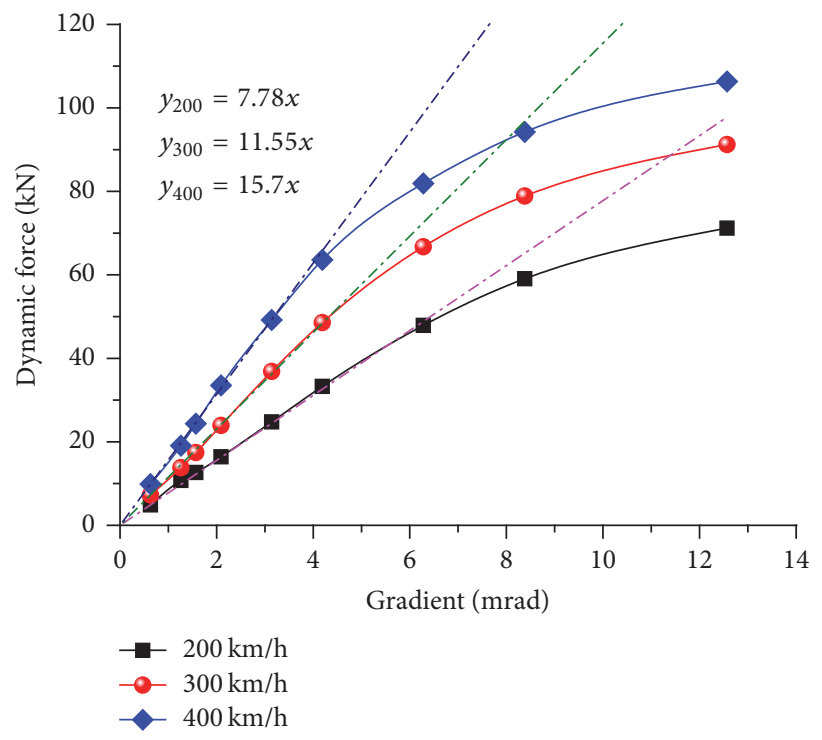

(a)

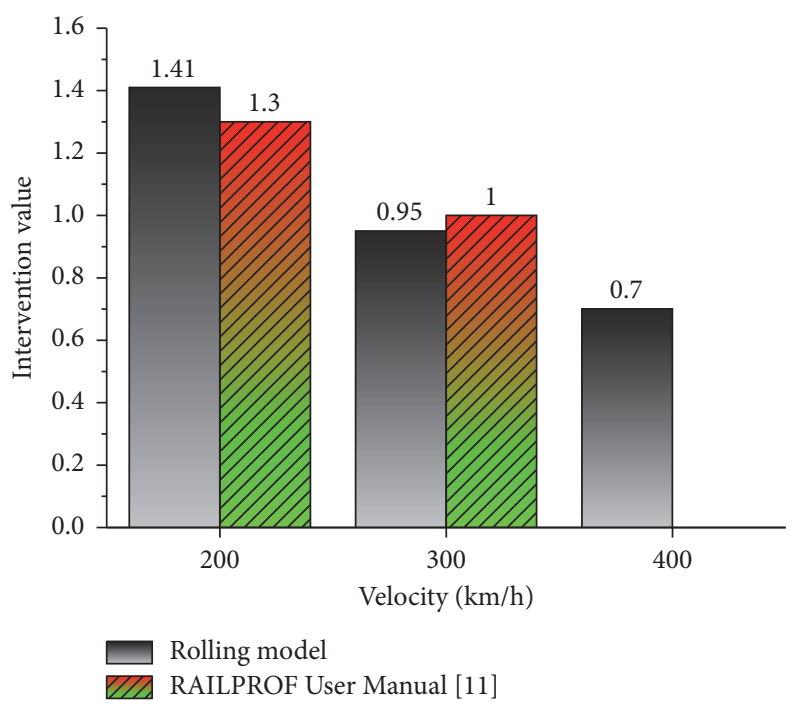

(b)

FIGURE 9: The influence of running speed on the (a) dynamic force and (b) intervention value.

4.3. Quantitative Relation of Dynamic Wheel-Rail Force and Axle-Box Acceleration. High-frequency vibration generated on the wheel-rail surface under excitation of all kinds of irregularities can be easily transferred to the axle box. However, previous studies on the axle-box acceleration [1417] have only focused on the use of response of the axle-box acceleration in frequency domain to monitor defects without any threshold proposed for safety running. In this section, based on results of Section 3, dynamic wheel-rail force and axle-box acceleration are used to establish a quantitative relation. Safety limits during the vehicles' running have been proposed from the view of the axle-box acceleration and can be applied on measured data as reported in [22].

Taking into account the cases in Section 3, the relation of axle-box acceleration and maximum dynamic force is established, as shown in Figure 10. Corresponding fitting curve is expressed as follows:

$$
F_{\text {dyn,max }}=0.41 \cdot \mathrm{ABA} .
$$

The figure shows that the corresponding axle-box acceleration against the safety limit of $90 \mathrm{kN}$ is $220 \mathrm{~m} / \mathrm{s}^{2}$. The relation between axle-box acceleration and $F_{\text {dyn,max }}$ at the speeds of $200 \mathrm{~km} / \mathrm{h}$ and $400 \mathrm{~km} / \mathrm{h}$ is also obtained in this paper. It is further found that the expression is almost the same as that of (9), which indicates that this relationship is not limited by the speed. Therefore, $220 \mathrm{~m} / \mathrm{s}^{2}$ can be regarded as a criterion if we have the measured data which has been processed by $1500 \mathrm{~Hz}$ LPF.

\section{Engineering Cases Study: Evaluation of Dynamic Force Based on Measured Rail Welds and Axle-Box Acceleration}

5.1. Measured Rail Welds. The discussion of the above results was based on the theoretical rail welds to facilitate the analysis

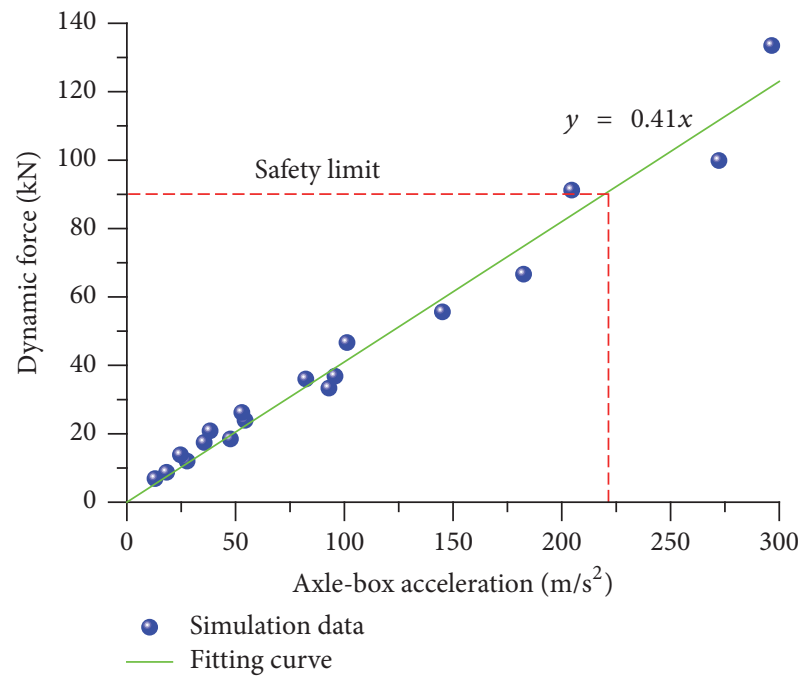

Figure 10: The relation of axle-box acceleration and maximum dynamic force under $300 \mathrm{~km} / \mathrm{h}$.

of the dynamic characteristics. However, weld irregularities observed on site are often complex. In this section, the focus is to evaluate dynamic force of four measured rail welds as described in Section 2.3.

5.1.1. Case 1. As described in Section 4.1, the QI method is used for judging whether the dynamic force at the rail weld is more than $11 \mathrm{kN}$. This indicator is generally used for the quality assessment of new built lines or after maintenance. Such a low dynamic force can ensure an adequate safety space. In Figure 11, RW1 is an early weld geometry and its gradient change is also included with a maximum gradient of 1.33 . This value is greater than the intervening value (0.95), which means that the rail weld does not meet the criterion and grinding should be carried out. 

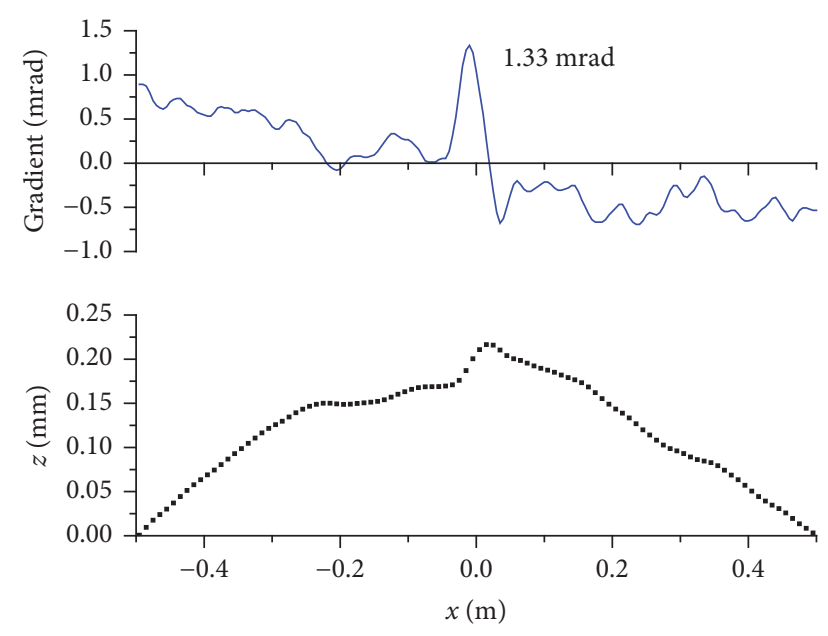

FIGURE 11: RW1 and its gradient distribution.

5.1.2. Case 2. Due to the repeated rolling of the wheels, the surfaces of the rail welds will gradually form local irregularities. The dynamic force excited by such a rail weld is generally greater than the limit $(11 \mathrm{kN})$ stipulated in the QI method. For daily operations, the excited dynamic force shall not exceed $90 \mathrm{kN}$ to ensure the riding safety. The evaluation of the dynamic force for this kind of weld has been elaborated in this section.

The rail weld RW2 shown in Figure 12 is a complex irregularity. The maximum gradient and excited dynamic forces in $300 \mathrm{~km} / \mathrm{h}$ are $4.69 \mathrm{mrad}$ and $42.95 \mathrm{kN}$, respectively. As the change of dynamic force is almost consistent with that of the geometric gradient, time change of the dynamic force will not be shown and only maximum dynamic force is illustrated in the following parts.

It is noted that the result of RW2 is located in the curve of the gradient and dynamic force at a depth of $0.1 \mathrm{~mm}$ in Figure 8, although its straightness is $0.1652 \mathrm{~mm}$. This is related to the characteristic depth of the actual geometry of the weld and an approach is proposed below to identify this depth.

As stated in Section 2.3 and shown in Figure 3, there are three zero values for the gradient which are corresponding to the starting, peak, and ending points of the rail weld, where both the starting and peak points determine the depth $d$ of the geometry. The authors marked this characteristic depth for RW2 in Figure 12(a), and the value is $0.11 \mathrm{~mm}$. It well explains the reason where the weld's result is located in Figure 8. It can be anticipated even if the weld straightness was $0.2 \mathrm{~mm}$; its characteristic depth will still be less than $0.2 \mathrm{~mm}$. Therefore, the maximum dynamic force is difficult to reach the limit value $(92 \mathrm{kN})$ as shown in Figure 8. It further explains that the existing straightness method can well ensure the safety service of wheel-rail systems in the welding zones. Meanwhile, the authors suggest that it can appropriately relax the requirements of straightness for such welds.

It is necessary to point out that the gradient in the range of $11 \mathrm{kN}$ has a linear relationship with the dynamic force and is independent of the depth, as shown in Figure 8. Therefore, the early weld mentioned in Section 5.1 .1 can be judged directly with the QI method for its small gradient.
5.1.3. Cases 3 and 4. Because of high temperature welding, materials in welds and heat-affected zone are often different from the base metal, reflecting in low yield strength and hardness [4]. Therefore, materials in that zone are prone to low collapse due to plastic deformation or wear. Its manifestation is shown in Figure 13. The gradients of these two welds are $4.34 \mathrm{mrad}$ and $5.72 \mathrm{mrad}$, respectively. Corresponding dynamic force excited is $45.67 \mathrm{kN}$ and $60.86 \mathrm{kN}$. These two diagrams also show their characteristic depths as $0.132 \mathrm{~mm}$ and $0.208 \mathrm{~mm}$.

It should be noted that the characteristic depths of the two welds in Figure 13 are the same as straightness, which are different from that in Figure 12. The phenomenon is caused by the opposite direction of the superimposed waveform. In Figure 12, the principal wave (or long wave) of the weld is convex, and the complementary wave (or the waveform corresponding to the characteristic depth) is also convex. Thus, the characteristic depth is less than its straightness. In Figure 13, the principal wave of RW3 is concave, while the complementary wave is convex. So the principal wave does not affect the depth of the complementary wave. RW4 is similar to that.

5.2. Measured Axle-Box Acceleration. Figure 14 gives the curve of the $\mathrm{ABA}$ changing along with the running time, which is measured at the speed of $300 \mathrm{~km} / \mathrm{h}$ in Chinese highspeed railway. The axle-box acceleration sensor is installed on the upper side of the axle-box end cover. In order to accurately obtain the vibration characteristics, the sampling frequency of the axle-box acceleration sensor is set to be $5000 \mathrm{~Hz}$. However, $1500 \mathrm{~Hz}$ LPF was imposed on the original signals with the consideration of typical frequency range of wheel-rail interaction and noises contained in high-frequency signals. Amplitude of ABA is generally fluctuated within the range of $\pm 50 \mathrm{~m} / \mathrm{s}^{2}$ under high-speed rolling conditions on account of existence of irregularities on the surface of wheel and rail. Rails of existing jointless track are welded at an interval of $100 \mathrm{~m}$. Thus, the pulse impulsion will arise every $1.2 \mathrm{~s}$ (it is about $100 \mathrm{~m}$ by calculating with the speed of $300 \mathrm{~km} / \mathrm{h}$ or $83.3 \mathrm{~m} / \mathrm{s}$ ), whose amplitude can reach $68 \sim 163 \mathrm{~m} / \mathrm{s}^{2}$, below the safety limit suggested in this paper.

The Cumulative Distribution Function (CDF) is shown in Figure 15 by using (9) to evaluate the dynamic forces on the peak of the ABA of 17 sets of welds in Figure 14. It can be seen that the maximum dynamic force in the data is $66.7 \mathrm{kN}$, far smaller than the safety limit $(90 \mathrm{kN})$. It is also observed that the dynamic force at the $94.1 \%$ of the welds is less than $61 \mathrm{kN}$; that is, the dynamic effect of the weld at most of the life cycle is less than this value, which is similar to the result in Figure 12: the dynamic force excited by RW4, in later period of life cycle, is about $60.8 \mathrm{kN}$. That is why dynamic forces at most parts of welds are below $61 \mathrm{kN}$.

\section{Discussion}

Gao et al. [1] tested 74 sets of rail welds in China's high-speed lines and classified them into three types according to the waveform superimposition, namely, the three welds shown in 


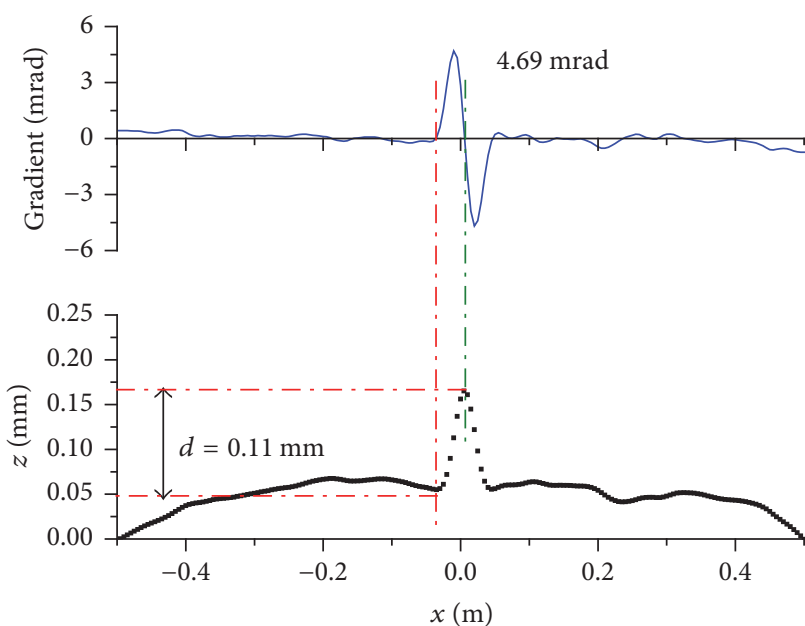

(a)

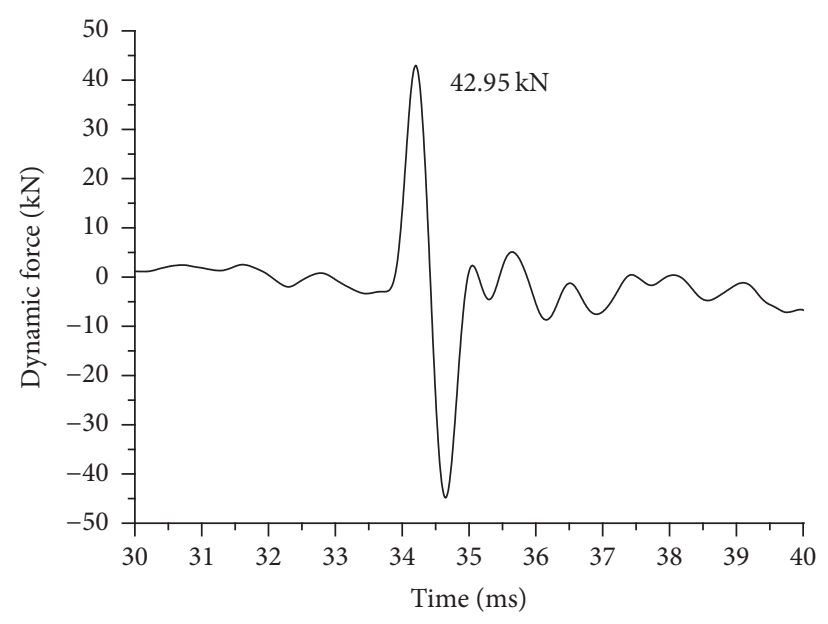

(b)

Figure 12: The (a) gradient of measured rail weld RW2 and (b) its excited dynamic force under $300 \mathrm{~km} / \mathrm{h}$.

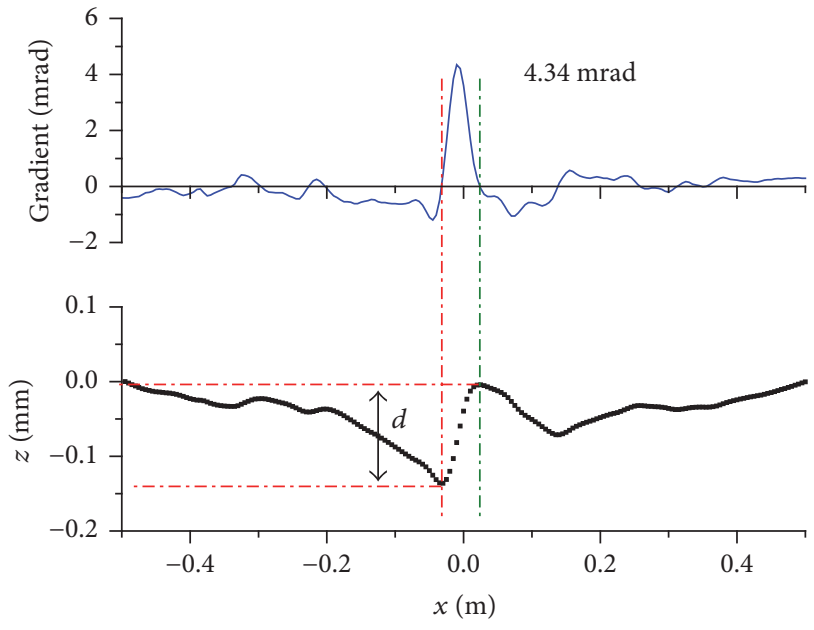

(a)

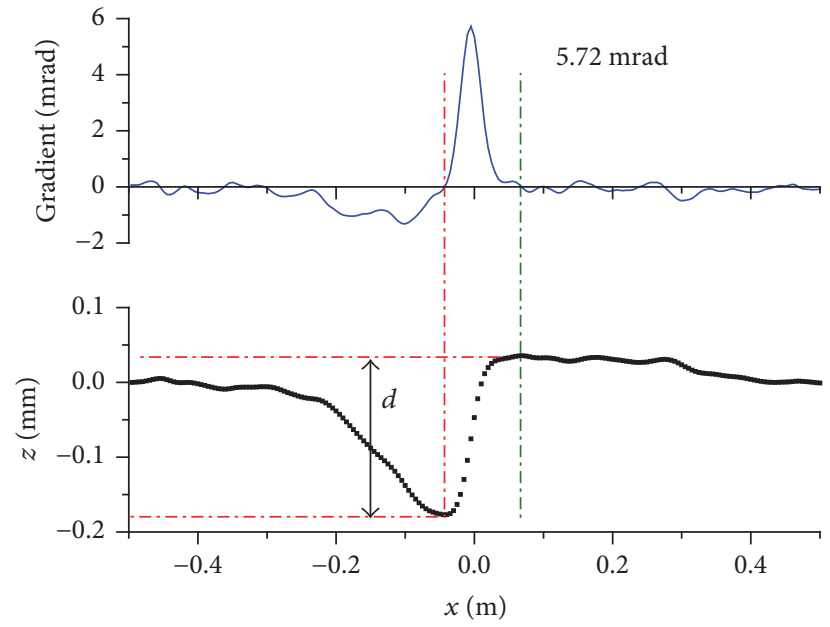

(b)

FIGURE 13: Two measured welds of (a) RW3 and (b) RW4 and their corresponding gradient distribution.

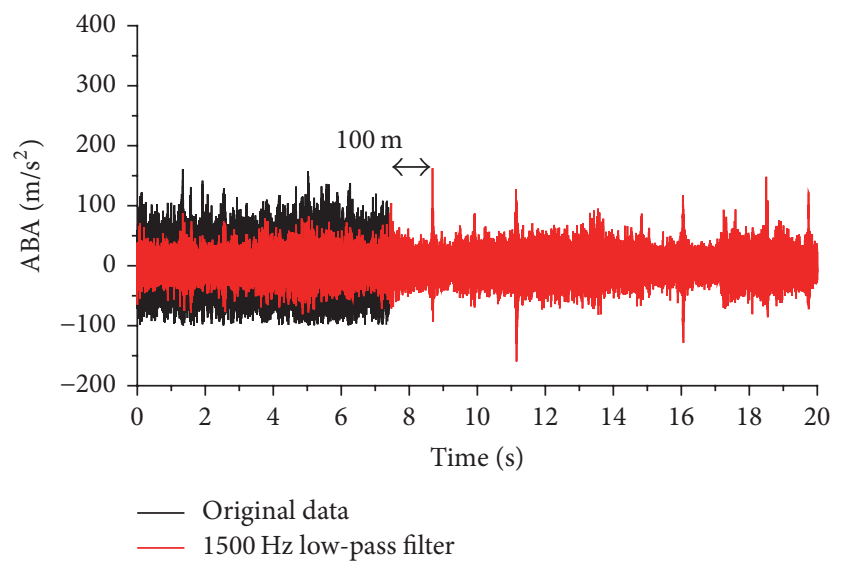

FIGURE 14: The response of measured axle-box acceleration when a vehicle is operated at the speed of $300 \mathrm{~km} / \mathrm{h}$ and its $1500 \mathrm{~Hz} \mathrm{LPF}$ results.
Figures 12 and 13. It is necessary to note that Figures 11 and 12 were classified as the same type in [1]. Thus, the four weld geometries of Figures 11-13 are representative. A discussion about evolution of the weld in the life cycle is presented accordingly.

The curve relationship between the gradient and dynamic force at different depths is plotted using formula (8) (see Figure 16). Results of the above four welds are also included. RW1 is located in the linear interval of the curve due to its small gradient, which is generally at the beginning stage of life cycle and can only excite small dynamic force. However, due to the maximum slope of this linear interval, (i.e., the dynamic force will increase significantly with the increase of the gradient), RW1 will gradually evolve into RW2 which can stimulate a higher dynamic force. The straightness of the weld will be gradually reduced due to plastic deformation or wear. However, its dynamic effect will remain stable for a 


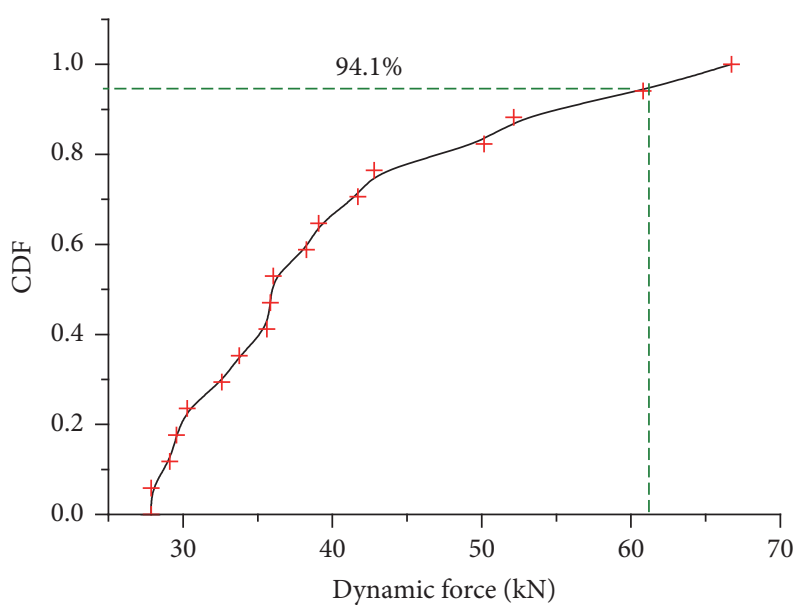

FIGURE 15: The relationship between axle-box acceleration and wheel-track force.

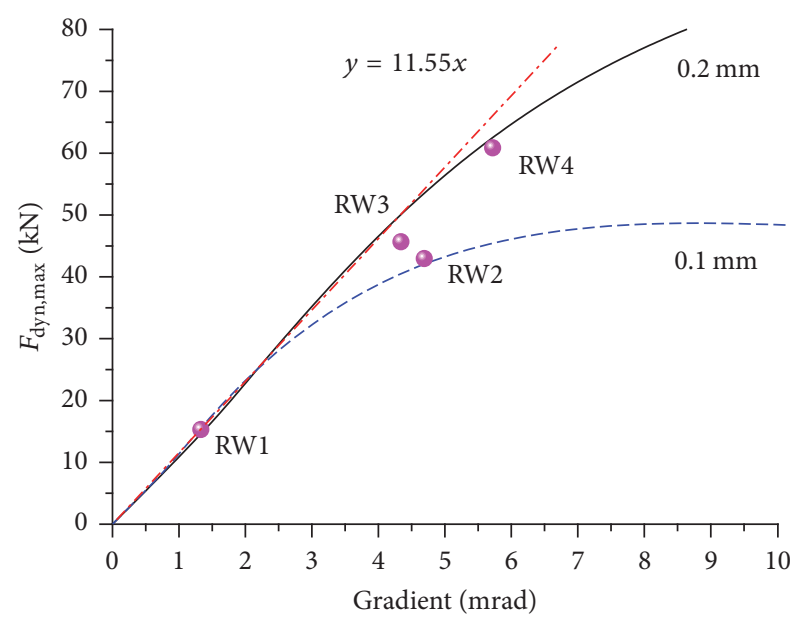

FIGURE 16: Distribution of dynamic forces at four rail welds.

long period. It is because the change of geometric shape in the weld is mainly located in two softening material zones, that is, $-0.035 \mathrm{~m}$ and $0.045 \mathrm{~m}$, as shown in Figure 12(a). The complementary wave can be stable for a long time. It can also be seen that the dynamic force grows slowly under the corresponding curve of the depth from the location of RW2 in Figure 16. Once the weld has evolved into RW3 or RW4, the rate of deterioration will be increased dramatically. The reason is that the continuous improvement of the straightness of the weld is directly reflected on the increase of the characteristic depth of the complementary wave. On one hand, the greater the depth is, the easier the dynamic force can be improved. That is, even if the RW3 gradient is smaller than RW2, RW3 has a higher dynamic force. On the other hand, the deepening depth will significantly increase the gradient, as shown in RW4 of Figure 16. Therefore, the weld in the later period should be ground as early as possible, avoiding its continued deterioration leading to rail replacement or even a security accident. The discussion above agrees with the evolution law of a measured rail weld reported in [23].

\section{Conclusion}

The dynamic wheel-rail interaction at the theoretical and the measured rail welds has been solved with help of rolling model established in this paper. Three methods treating relationship among geometrical gradient, wheel-rail force, and axle-box acceleration have been obtained. Based on simulated results, the following conclusions can be reached.

(1) Considering the maximum depth of $0.2 \mathrm{~mm}$ stipulated by the existing straightness, the rolling model established was utilized to solve the dynamic effect of the wavelength welds from 0.03 to $1 \mathrm{~m}$. It is found that the maximum dynamic force is $92 \mathrm{kN}$ or 2.2 of DAF. It is in line with the actual operating state and proves the rationality of the existing maintenance rules for high-speed railway lines.

(2) When the gradient is small, the dynamic force will be linearly related to the gradient. The improvement of vehicle speed could increase the slope of the linearity. On this basis, the intervention values at the speeds of $200 \mathrm{~km} / \mathrm{h}$ and $300 \mathrm{~km} / \mathrm{h}$ are 1.41 and 0.95 , which are close to the standard proposed by RAILPROF. Thus, it proved the effectiveness of the numerical values and further proposed the intervention value of 0.7 for the line of $400 \mathrm{~km} / \mathrm{h}$.

(3) Based on the measured geometries, the wheel-rail interactions of four typical weld irregularities have been simulated. The evolution process in the life cycle has been discussed on the basis of the geometric characteristics and dynamic effect: local irregularities were quickly transformed from the geometrical profile of the early weld. The characteristic depth of the irregularity could be developed stably and evolved into a concave form. Soon afterwards, it is quickly developed to the late period.

(4) The quantitative relationship between the dynamic force and ABA has been established by the rolling model. Such ABA is preprocessed with $1500 \mathrm{~Hz}$ LPF with the consideration of typical frequency range of wheel-rail interaction and noises contained in high-frequency signals. According to dynamic force threshold $(90 \mathrm{kN})$ used in Chinese high-speed railway, it suggests $\mathrm{ABA}$ of $220 \mathrm{~m} / \mathrm{s}^{2}$ (upon $1500 \mathrm{~Hz} \mathrm{LPF}$ ) as the safety limit for rail welds.

This work only considers a typical kind of high-speed railway track and vehicle. For the further study, it is necessary to investigate the influence of more parameters (vehicle's suspension parameters, different rail supports, degradation of track stiffness, etc.) on relationship among geometric gradient, dynamic wheel-rail force, and ABA.

\section{Conflicts of Interest}

The authors declare that there are no conflicts of interest regarding the publication of this paper.

\section{Acknowledgments}

The present work has been supported by the National Key R\&D Plan of China (2016YFC0802203-4), the National Natural Science Foundation of China (51425804, 51608459, 
and 51778542), and Doctoral Innovation Fund Program of Southwest Jiaotong University.

\section{References}

[1] J. Gao, W. Zhai, and Y. Guo, "Wheel-rail dynamic interaction due to rail weld irregularity in high-speed railways," Proceedings of the Institution of Mechanical Engineers, Part F: Journal of Rail and Rapid Transit, 2016.

[2] G. Kouroussis, D. P. Connolly, and O. Verlinden, "Railwayinduced ground vibrations-a review of vehicle effects," International Journal of Rail Transportation, vol. 2, no. 2, pp. 69-110, 2014.

[3] C. Esveld, Modern Railway Track, MRT-Productions, Zaltbommel, The Netherlands, 2001.

[4] P. J. Mutton and E. F. Alvarez, "Failure modes in aluminothermic rail welds under high axle load conditions," Engineering Failure Analysis, vol. 11, no. 2, pp. 151-166, 2004.

[5] P. J. Webster, G. Mills, X. D. Wang, W. P. Kang, and T. M. Holden, "Residual stresses in alumino-thermic welded rails," Journal of Strain Analysis for Engineering Design, vol. 32, no. 6, pp. 389400, 1997.

[6] A. Skyttebol, B. L. Josefson, and J. W. Ringsberg, "Fatigue crack growth in a welded rail under the influence of residual stresses," Engineering Fracture Mechanics, vol. 72, no. 2, pp. 271-285, 2005.

[7] W. M. Zhai, C. B. Cai, Q. C. Wang, Z. W. Lu, and X. S. Wu, "Dynamic effects of vehicles on tracks in the case of raising train speeds," Proceedings of the Institution of Mechanical Engineers, Part F: Journal of Rail and Rapid Transit, vol. 215, no. 2, pp. 125135, 2001.

[8] G. Xiao, X. Xiao, J. Guo, Z. Wen, and X. Jin, “Track dynamic behavior at rail welds at high speed," Acta Mechanica Sinica, vol. 26, no. 3, pp. 449-465, 2010.

[9] M. J. M. M. Steenbergen and C. Esveld, "Rail weld geometry and assessment concepts," Proceedings of the Institution of Mechanical Engineers, Part F: Journal of Rail and Rapid Transit, vol. 220, no. 3, pp. 257-271, 2006.

[10] M. J. M. M. Steenbergen and C. Esveld, "Relation between the geometry of rail welds and the dynamic wheel-rail response: Numerical simulations for measured welds," Proceedings of the Institution of Mechanical Engineers, Part F: Journal of Rail and Rapid Transit, vol. 220, no. 4, pp. 409-423, 2006.

[11] RAILPROF User Manual, http://www.railprof.com/.

[12] TB 28-2008, Testing of High-speed Electic Multiple Unit on Completion of Construction, China Railway Corporation, Beijing, China, 2008.

[13] S. L. Grassie, "Measurement of railhead longitudinal profiles: A comparison of different techniques," Wear, vol. 191, no. 1-2, pp. 245-251, 1996.

[14] B. Liang, S. D. Iwnicki, Y. Zhao, and D. Crosbee, "Railway wheelflat and rail surface defect modelling and analysis by timefrequency techniques," Vehicle System Dynamics, vol. 51, no. 9, pp. 1403-1421, 2013.

[15] M. Molodova, M. Oregui, A. Núñez, Z. Li, and R. Dollevoet, "Health condition monitoring of insulated joints based on axle box acceleration measurements," Engineering Structures, vol. 123, pp. 225-235, 2016.

[16] Z. Li, M. Molodova, A. Nunez, and R. Dollevoet, "Improvements in axle box acceleration measurements for the detection of light squats in railway infrastructure," IEEE Transactions on Industrial Electronics, vol. 62, no. 7, pp. 4385-4397, 2015.
[17] M. Molodova, Z. Li, and R. Dollevoet, "Axle box acceleration: measurement and simulation for detection of short track defects," Wear, vol. 271, no. 1-2, pp. 349-356, 2011.

[18] P. Wang, B. An, J. Xiao, J. Xu, and R. Chen, "Health condition simulation of rail weld in high-speed railway based on geometric gradient and axle-box acceleration," in Proceedings of the World Congress on Advances in Structural Engineering and Mechanics (ASEM '17), vol. 1, Seoul, Korea, 2017.

[19] X. Zhao, Z. Wen, H. Wang, X. Jin, and M. Zhu, "Modeling of high-speed wheel-rail rolling contact on a corrugated rail and corrugation development," Journal of Zhejiang University SCIENCE A, vol. 15, no. 12, pp. 946-963, 2014.

[20] G. Kouroussis, D. P. Connolly, G. Alexandrou, and K. Vogiatzis, "Railway ground vibrations induced by wheel and rail singular defects," Vehicle System Dynamics, vol. 53, no. 10, pp. 1500-1519, 2015.

[21] X. Zhao, B. An, X. Zhao, Z. Wen, and X. Jin, "Local rolling contact fatigue and indentations on high-speed railway wheels: Observations and numerical simulations," International Journal of Fatigue, vol. 103, pp. 5-16, 2017.

[22] W. Zhai, P. Liu, J. Lin, and K. Wang, "Experimental investigation on vibration behavior of a CRH train at speed of $350 \mathrm{~km} / \mathrm{h}$," International Journal of Rail Transportation, vol. 3, no. 1, pp. 116, 2015.

[23] J. Xu, P. Wang, Y. Gao, J. Chen, and R. Chen, "Geometry evolution of rail weld irregularity and the effect on wheel-rail dynamic interaction in heavy haul railways," Engineering Failure Analysis, vol. 81, pp. 31-44, 2017. 


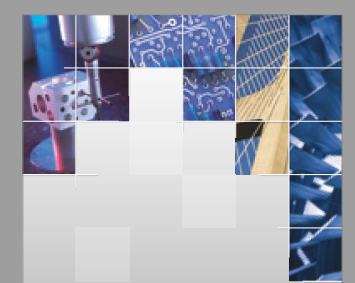

\section{Enfincering}
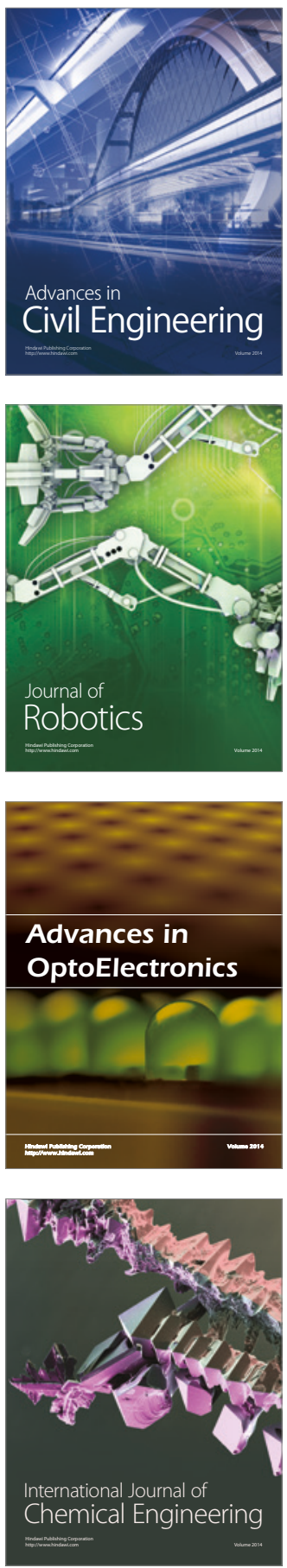

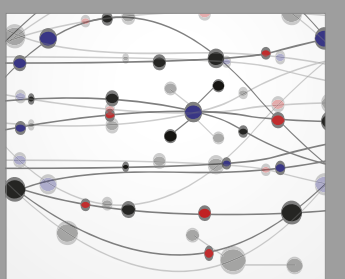

The Scientific World Journal

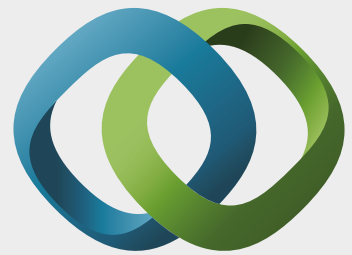

\section{Hindawi}

Submit your manuscripts at

https://www.hindawi.com
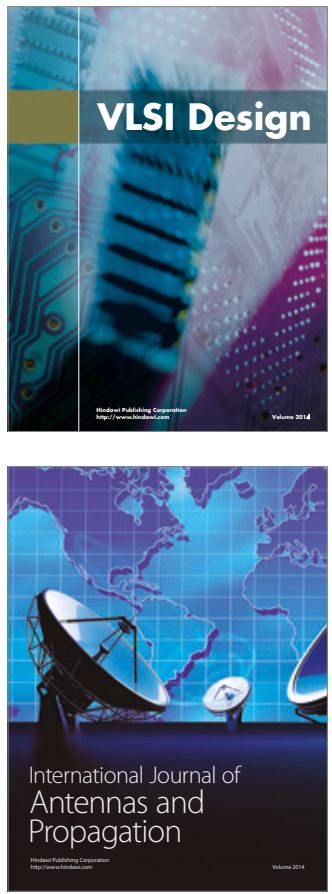

\section{Rotating}

Machinery
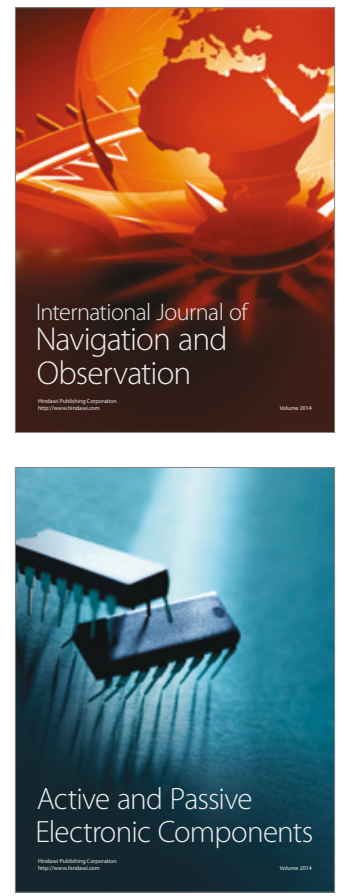
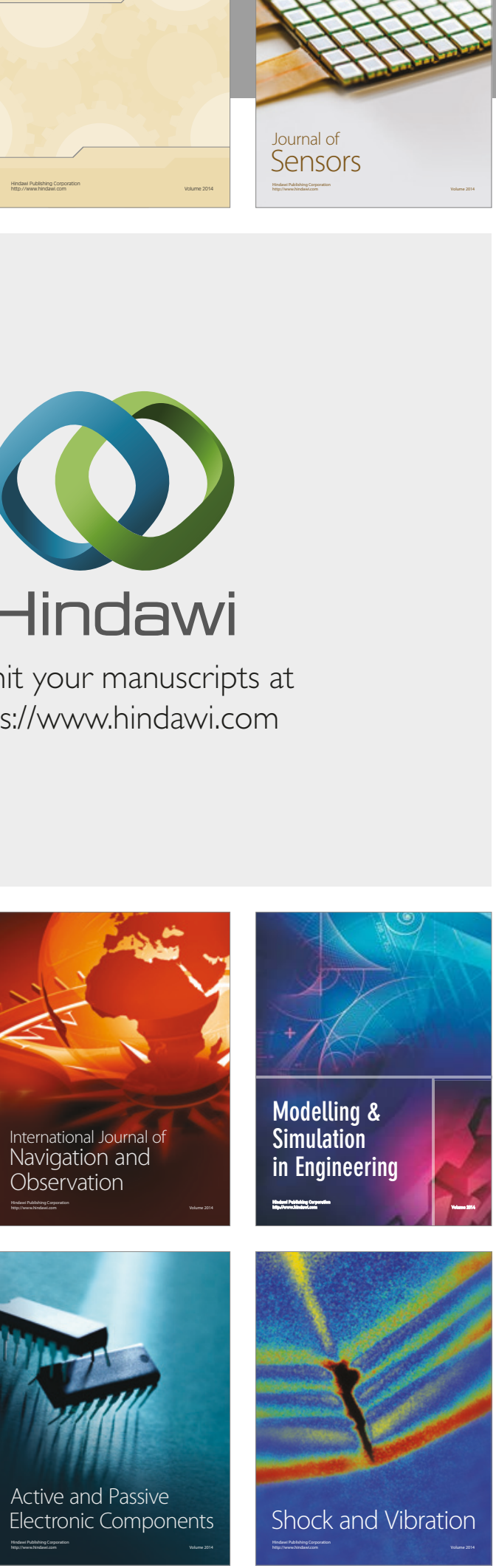
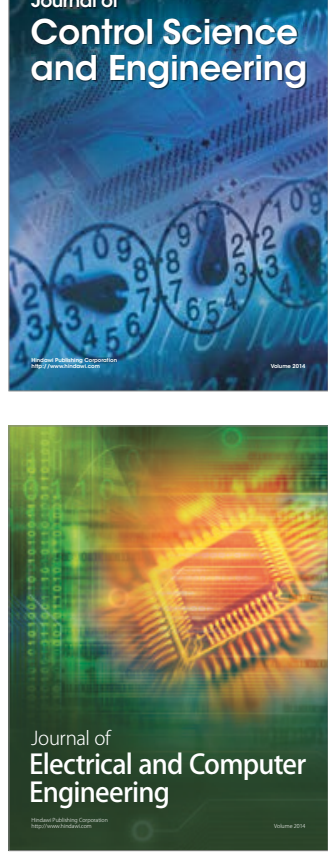

Distributed

Journal of

Control Science

and Engineering
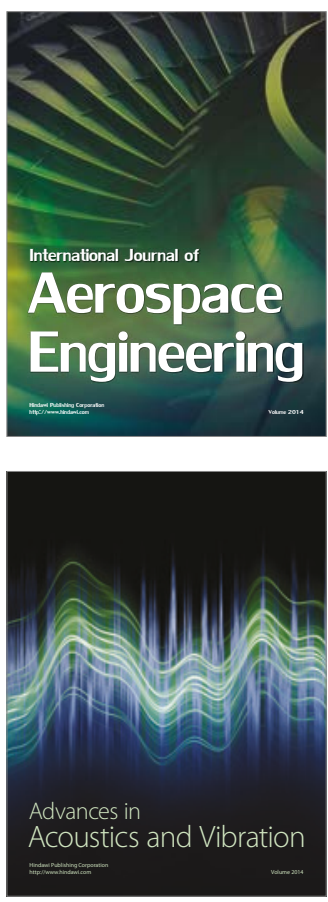

Sensor Networks 